\section{Vigilancia de los efectos adversos de los fármacos}

\section{Sr. Director:}

Hemos leído con interés la carta al director ${ }^{1}$ publicada en esta revista, como respuesta al caso clínico que presentamos, titulado "Síndrome de poliartritis por antitiroideos", y sobre la cual queríamos hacer algunas puntualizaciones:

-El médico de Atención Primaria inicialmente debería conocer los efectos adversos más frecuentes de los fármacos, pero también de los potencialmente más peligrosos, aunque poco frecuentes. En el caso de los fármacos antitiroideos, aunque sus efectos adversos sean poco frecuentes y se hayan publicado pocos $\operatorname{casos}^{3}$ (no significa existentes, porque algunos no habrán sido publicados, y otros ni siquiera sospechados), nunca se nos puede olvidar pensar en una agranulocitosis. Sospechar efectos secundarios como el que nos ocupa (artritis) y otros como alteraciones cutáneas, trastornos gastrointestinales, etc. nos ayudaría a evitar pruebas diagnósticas innecesarias y poder instaurar un tratamiento inmediato, pero el no sospecharlo no pondría inicialmente en peligro la vida del paciente.

-Existen discrepancias en la literatura, respecto al fármaco antitiroideo que más efectos secundarios presenta. Algunos autores señalan que los efectos secundarios son más frecuentes con propiltiouracilo (no comercializado en España), que con carbimazol o metimazol ${ }^{4}$. Por otra parte, Richard ${ }^{5}$ señala que los efectos secundarios son similares para todos los fármacos, y Cooper $^{6}$ que cada fármaco produce de forma más frecuente un determinado tipo de efecto adverso.

- Ante la aparición de un efecto adverso con una tionamida, aún contando con que existe un $20-50 \%$ de probabilidad de que se repita la reacción adver$\mathrm{sa}^{5,7,8}$ no implica la no utilización de otra, debiendo valorarse la gravedad de dicho efecto adverso. Los pacientes que tienen un efecto secundario grave con algún fármaco antitiroideo (como hepatitis, vasculitis, agranulocitosis) no deberían recibir un tratamiento de prueba con otro fármaco debiendo utilizar el $\mathrm{I}^{131}$ o la tiroidectomía subtotal ${ }^{6,7}$. Pero si el efecto secundario es leve (como alteración cutánea, etc.) podría intentarse con precaución el tratamiento con otro fármaco antitiroideo $^{6}$.

\section{B. Sanz Pozo, J. L. Quintana Gómez}

Especialistas de Medicina Fami liar y Comunitaria. Centro de Salud. Área 10. Getafe. Madrid

\section{BIBLIOGRAFÍA}

1. Zufía FJ, Ruiz R, López B. Síndrome de artritis por antitiroideos. Medifam 2001; 11: 416.

2. Sanz B, Quintana JL, Gónzalez AI. Síndrome de poliartritis por antitiroideos. Medifam 2001; 11: 92-6.

3. Mathieu E, Fain O, Sitbon M, Thomas M. Systemic adverse effect of antithyroid drugs. Clin Rheumatol 1999; 18: 66-8. 
4. Bartalena L, Bogazzi F, Martino E. Adverse effects of thyroid drugs. Drug Safety 1996; 15: 53-63.

5. Richard AJ. Antithyroid arthritis syndrome-a case induced by carbimazole. J Rheumatol 1999; 26: 1851.

6. Cooper DDS. Antithyroid drugs for the treatmente of hyperthyroidism cause by Graves disease. Endocrinol Metab Clin North Am 1998; 27: 225 32.

7. Manero RFJ, Playan UJ, Acha PJ, Sanz PA. Methimazole arthritis in Graves Basedow disease. An Med Interna 1998; 15: 47-8.

8. Gittoes NJL, Franklyn JA. Hyperthyroidism. Current treatment guidelines. Drugs 1998; 55: 543-53.

\section{Enfermedad de Mondor. A propósito de un caso}

\section{Sr. Director:}

La enfermedad de Mondor es una entidad clínica rara y relativamente poco conocida. El cuadro clínico fue apuntado inicialmente por Fagge en 1869, posteriormente se recogieron casos esporádicos hasta que el cirujano francés Henri Mondor la describe en 1939, dándole su nombre. En 1976 se publica el primer caso en nuestro país ${ }^{1}$.

Esta enfermedad se caracteriza por una flebitis y periflebitis de una vena superficial del tórax, la vena torácica lateral o toracoepigástrica, que puede extenderse hacia la pared abdominal en la región epigástrica ${ }^{2}$, y en la mujer también a la piel de la mama ${ }^{3}$. Afecta principalmente a mujeres entre 21 y 55 años, aunque en un tercio de los casos puede aparecer en el varón.

La sintomatología se caracteriza por la aparición brusca de dolor en mama y/o pared anterior de tórax, seguida de la aparición de un cordón, estría o canal visible y palpable, doloroso en dicha zona.
Su etiología es desconocida pudiéndose relacionar en algunos casos con traumatismo local, esfuerzo muscular, procedimientos quirúrgicos en la mama y procesos febriles previos ${ }^{4}$. No parece existir relación con el cáncer de mama aunque se han descrito casos asociados al mismo ${ }^{5,6}$. También se han referido casos asociados a embarazo y puerperio ${ }^{7}$, a la arteritis de células gigantes ${ }^{8} \mathrm{y}$ a otras enfermedades sistémicas.

La imagen mamográfica puede ser característica con la vena trombosada presentando una morfología alargada o como las cuentas de un collar.

En la ecografía la vena se identifica como una estructura tubular hipoecoica con segmentos alternantes dilatados y engrosados.

Habitualmente evoluciona espontáneamente hacia la curación, si bien en ocasiones puede evolucionar a la cronicidad y complicarse con pequeñas necrosis cutáneas sobre la zona de la vena trombosada.

Presentamos el caso clínico de una mujer de 29 años que acude a consulta por presentar bruscamente un bulto, como un cordón discretamente doloroso en la zona anterior del tórax, inframamario y que aumenta con la hiperextensión del brazo del mismo lado.

Entre los antecedentes personales destacan ser fumadora habitual de diez cigarrillos al día. No refiere traumatismo previo ni otro proceso inflamatorio local, ni tampoco fiebre ni alteración del estado general. Los antecedentes familiares sin interés.

En la exploración se observaba en la cara anterolateral izquierda de tórax un cordón doble longitudinal con un surco o canal de unos $8 \mathrm{~cm}$ ligeramente doloroso a la palpación, cuyo trayecto terminaba en la zona central de la mama izquierda; dicho cordón se hacia más visible y palpable con la elevación de la mama (Figs. 1 y 2). No se apreciaba enrojecimiento ni aumento de temperatu-

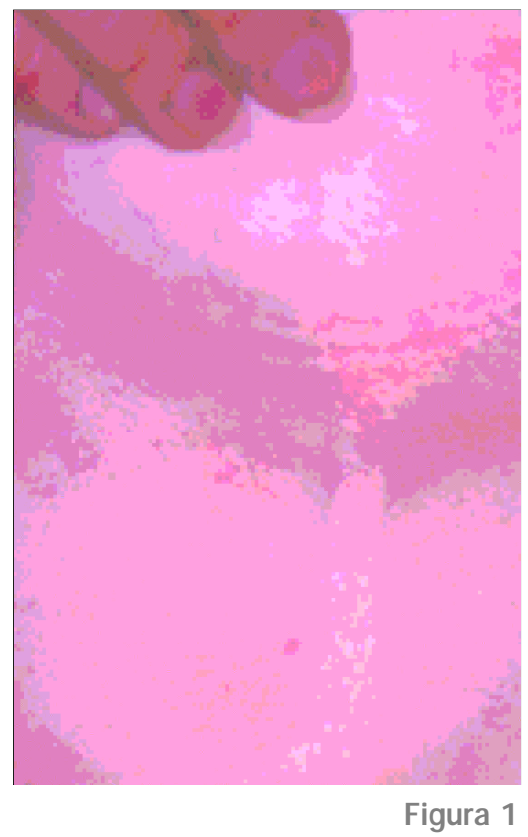

Imagen donde se aprecia el cordón longitudinal doble a nivel inframamario izquierdo

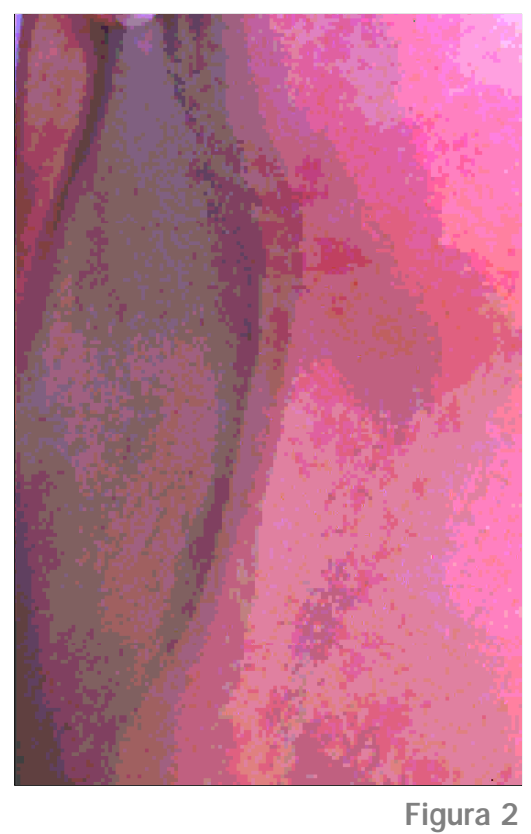

Con la elevación del brazo y la mama izquierdos se observa más nítidamente el cordón con un surco

central

ra a dicho nivel, tampoco se palpaba ninguna tumoración en las mamas ni tampoco adenopatías axilares ni supraclaviculares.

Se pautó tratamiento antiinflamatorio, se solicitó analítica 